\title{
National Health Insurance Databases in Indonesia, Vietnam and the Philippines
}

\author{
Junice Yi Siu Ng ${ }^{1} \cdot$ Royasia Viki Ramadani ${ }^{2} \cdot$ Donni Hendrawan $^{3} \cdot$ Duong Tuan Duc $^{4} \cdot$ Pham Huy Tuan Kiet $^{5}$
}

Published online: 11 March 2019

(c) The Author(s) 2019

\begin{abstract}
Background Social health insurance administrative databases were established in Indonesia, Vietnam and the Philippines in 2014, 2017 and 2012, respectively; however, these databases have been scarcely used for research, if at all. This study explored the feasibility and accessibility of using these databases for scientific research, highlighting challenges and barriers in their use.

Methodology The databases included in this evaluation comprised the Jaminan Kesehatan Nasional (JKN) from Indonesia, Vietnam Health Insurance Scheme (VHIS) from Vietnam and PhilHealth from the Philippines. These databases were qualitatively assessed based on the data capture, potential linkage to other databases or registries, data access and extraction, privacy and security, and quality and validation procedures.

Results All databases contain population-based cohort data on the medical costs of reimbursed medical conditions, identified using International Classification of Diseases, Tenth Revision (ICD-10) codes. Linkage to other national databases, ensuring protection of patient privacy data, would improve their usability. Duration to database access and data extraction varies from country to country. The main limitations of all databases include the short span of data records, and the unknown degree of internal validity. Both JKN and PhilHealth databases capture bundled claims, inherently excluding information on prescriptions and out-of-pocket expenditure. Due to the recent establishment of the VHIS database, it may not be suitable for studies that intend to explore trends.

Conclusion The JKN, VHIS and PhilHealth databases offer population-based, financial, utilization, and demographic data, which could provide valuable epidemiological and pharmacoeconomic insights if the findings are interpreted within the limitations of each database.
\end{abstract}

Electronic supplementary material The online version of this article (https://doi.org/10.1007/s41669-019-0127-2) contains supplementary material, which is available to authorized users.

\section{Junice Yi Siu Ng}

nysjunice@gmail.com

1 Real-World Insights, IQVIA Asia-Pacific, 79 Anson Road, \#19-01, Singapore 079906, Singapore

2 Center for Health Economics and Policy Studies, Faculty of Public Health, Universitas Indonesia, Beji, Kota Depok, Jawa Barat, Indonesia

3 Primary Health Care Financing, Badan Penyelenggara Jaminan Sosial Kesehatan, Jakarta, Indonesia

4 North Center for Medical Review and Tertiary Care Payment, Vietnam Social Security, Hanoi, Vietnam

5 Department of Health Economics, Hanoi Medical University, Hanoi, Vietnam

\section{Key Points for Decision Makers}

Social health insurance administrative databases in Indonesia, Vietnam and the Philippines contain data on healthcare resource utilization and reimbursed costs. Medical conditions can be identified using International Classification for Diseases, Tenth Revision (ICD-10) codes.

These databases offer an avenue for providing epidemiological and pharmacoeconomic information required for planning and allocating resources.

Future development should focus on linking databases to registries or hospital records to expand the scope of information. 


\section{Background}

Health status in Southeast Asia, where approximately half a billion people reside [1], has improved compared with a decade ago [2]. Life expectancy at birth has increased and crude mortality rate has decreased over the past decade [2]. This remarkable improvement could be partly attributed to the development of national social health insurance (SHI), a cornerstone of universal health coverage (UHC) [2]. However, the confluence of non-communicable diseases, persisting infectious diseases, and re-emergence of potentially pandemic infectious diseases will continue to stretch the already strained health systems. Several studies have harnessed the rich information captured in SHI administrative databases to assist in the prioritization of health initiatives and the allocation of resources [3-6]. These databases are also increasingly being used in observational studies in place of more resource-intensive study designs, such as randomized controlled trials, due to a better representation of population health and its direct applications to policymaking [5]. Nonetheless, these databases also have limitations, namely the under-ascertainment of severe or chronic diseases [7, 8], coding errors [9], lack of evidence on internal validity [10] and lack of specific information on treatment due to bundling of claims [11]. There could also be challenges in the procedural access to these national datasets due to privacy concerns [12].

\subsection{Health System, Social Health Insurance (SHI) and Coverage}

Although UHC has been rolled out in Indonesia, Vietnam and the Philippines, it remains a challenge to achieve universal coverage due to the sizeable populations. SHI in Indonesia (2014) and Vietnam (2015) were introduced later than in the Philippines (1995) [13]. While Indonesia and Vietnam operate on a single-payer system, the Philippines has a mixed-financing system of public insurer and private health expenditure, mainly sourced from out-of-pocket (OOP) spending. Intrinsically, it has the highest percentage of OOP health expenditure at 53\%, compared with Indonesia (48\%) and Vietnam (43\%), in 2015 [14].

\subsubsection{Indonesia}

Healthcare delivery is decentralized to local governments and is a mixed public-private system. The public sector is differentiated into three levels, with community healthcare centres (also known as Puskesmas) serving primary care, and hospitals providing secondary or tertiary care. National health insurance, known as Jaminan Kesehatan Nasional
(JKN), is managed by the national social security agency, Badan Penyelenggara Jaminan Sosial (BPJS) Kesehatan. Payments to primary care providers are through capitation and non-capitation schemes. Capitation schemes include primary care services for health promotion and prevention, medical treatment and consultations, drugs and laboratory tests. Services paid through non-capitation schemes include inpatient care, ambulance service, drugs and screening tests included in the back-referral programme for chronic diseases (also known as Program Rujuk Balik [PRB]), antenatal and neonatal services, and family planning in the primary care. PRB reimburses approximately 30 days of medications for chronic diseases, dispensed from BPJS-authorized retail pharmacies. Chronic conditions include hypertension, diabetes mellitus, asthma, chronic obstructive pulmonary disease, epilepsy, stroke, systemic lupus erythematosus, schizophrenia and chronic ischaemic heart disease. Payments to hospital providers are based on the Indonesia Case-Based Group (INA-CBG), a local Diagnosis-Related Group (DRG) equivalent. High-cost drugs such as anticancer medications are unbundled with the aim of better predicting their use. Patients receive full coverage for drugs identified in the national formulary at public hospitals [13].

\subsubsection{Vietnam}

Vietnam has a predominantly public hospital system [15]. The Vietnam Health Insurance Scheme (VHIS), managed by the Vietnam Social Security (VSS) agency, was introduced in 1992, but was made mandatory in 2015. While district hospitals and some provincial hospitals are based on the capitation system, most hospitals are reimbursed on a fee-for-service basis. Depending on the level of medical services and the insurance schemes (differentiated by types of employment), VHIS reimburses 80 to $100 \%$ of the cost of primary services and 40 to $100 \%$ of the cost of specialized services [13]. It covers medical examinations and care, preventive care, rehabilitation, maternity care and prescribed medications listed in the formulary.

\subsubsection{The Philippines}

The Philippines has a fragmented and decentralized healthcare delivery system, with well-established private healthcare providers coexisting with the public health system. The public system provides tertiary care at Department of Health (DOH)-governed hospitals, while local government units (LGUs) support secondary or primary care. The latter is a network of provincial and district hospitals (secondary care), rural health units and barangay health stations. Unlike Indonesia and Vietnam, primary healthcare is largely provided by private physicians. At tertiary level, there are private specialized and general hospitals that could either 
be for-profit or non-profit. The National Health Insurance Program generally supports $34 \%$ of the healthcare expenditure [16], and is managed by the Philippine Health Insurance Corporation (PhilHealth). It was formed in 1995 as a successor to the Medicare programme, and gained further traction in 2012 when 'sin taxes' on tobacco and liquor were introduced to generate resources for financing and expansion of UHC. Accredited healthcare providers offer inpatient and outpatient services that are paid directly by the health fund according to a fixed schedule (fee-for-service and case rates for select medical and surgical procedures). In case-based payment, also known as All-Case Rates (ACR), reimbursement rates for medical cases depend on International Classification of Diseases, Tenth Revision (ICD-10) codes, and surgical procedures are based on the Relative Value Scale (RVS) [17]. ACR generally covers inpatient treatment, which is limited to 45 days a year. Each enrolled member is covered, together with their spouse and all dependent children under 21 years of age. Medicines that are prescribed, including over-the-counter (OTC) drugs, are partially reimbursed under SHI if they are listed in the national formulary.

\subsection{SHI Databases}

Several high-income and upper middle-income countries in Southeast Asia, such as Singapore, Thailand and Malaysia, have established administrative claims systems as reliable data sources for public health research [18]. In recent years, Indonesia, Vietnam and the Philippines have also introduced the use of SHI administrative databases as a means of accessing national healthcare claims data for epidemiological and health economics research. The databases in Indonesia and Vietnam were fully established in 2014 and 2017, respectively, while the database in the Philippines was revamped in 2012 to accommodate changes in health financing. These health data repositories could be an important source of evidence for medical and policymaking decisions, given the paucity of timely and representative data in these countries. While no studies have been conducted using the claims database in Vietnam due to its recent establishment, a literature search on those in Indonesia and the Philippines has shown a limited strand of publications on population health research. Studies conducted using the Indonesian claims database revolve around healthcare utilization and evaluation on the hospital payment system [19-21]. Claims data in the Philippines have been used to study the prevalence and costs of hypertension, community-acquired pneumonia and congestive heart failure among hospitalized insured members [22-24], and has also been used to understand healthcare financing in the Philippines [25]. Plausible reasons for the limited use of these databases include the lack of guidelines for accessing these databases [18] and the lack of evaluation of these databases [5, 18]. The pathway to accessing these databases is also not available on the agencies' websites. This study aims to explore the feasibility and accessibility of using these databases for health research, and to illustrate the challenges involved in using these databases. It is not intended to compare the level of accessibility among the evaluated databases.

\section{Methodology}

This study was conducted between January and August 2018 by seven researchers from academia, government institutions and industry, of which five are authors of this article and two are acknowledged contributors. From each country, two researchers, one of whom was the data custodian, evaluated the databases based on a list of open-ended questions (Electronic Supplementary Material 1). The evaluation was not independent as the data custodian provided information about the database, while the other assessor clarified the information with the data custodian. The evaluation included a description of SHI data management, and components adapted from the Guidelines for Good Database Selection and Use in Pharmacoepidemiology Research [26], endorsed by the International Society for Pharmacoepidemiology, were used as the assessment framework. The specific components included in this evaluation are as follows.

Description of data capture Includes assessing the coverage of population and health facilities, data capture and its continuity and consistency, and recording the length and latency of medical visits in the database record.

Linkage to other databases or registries Refers to the expansion of the database by linking individual-level records in the database to other existing data sources.

Data access and extraction Specifies data access and extraction, and the export of data.

Privacy and security Refers to the procedures needed to adhere to local policy and legislation on privacy law.

Quality and validation Characterizes the steps taken by respective social security agencies to validate the data.

\section{Results}

\subsection{SHI Data Management}

Information on the assessed SHI and data management is summarized in Table 1. The JKN database was initiated in 
Table 1 Description of national health insurance and database management in Indonesia, Vietnam and the Philippines

\begin{tabular}{|c|c|c|c|}
\hline & Indonesia & Vietnam & Philippines \\
\hline Social security agency & $\begin{array}{l}\text { Badan Penyelenggara Jaminan Sosial } \\
\text { (BPJS) }\end{array}$ & Vietnam Social Security & Philippine Health Insurance Corporation \\
\hline National Social Health Insurance & Jaminan Kesehatan Nasional (JKN) & $\begin{array}{l}\text { Vietnam Health Insur- } \\
\text { ance Scheme (VHIS) }\end{array}$ & PhilHealth \\
\hline Started in & 2014 & $\begin{array}{l}\text { Introduced in } 1992 \text { and } \\
\text { mandatory by law in } \\
2015\end{array}$ & 1995 \\
\hline Primary care funding & Capitation & Fee-for-service & Capitation \\
\hline Inpatient care funding & INA-CBG (local equivalent of DRG) & Fee-for-service & Case rates (local equivalent of DRG) \\
\hline Database started in & 2014 & 2015 & $\begin{array}{l}\text { Electronic claims processing started in } \\
\text { 1995, but revamped in } 2012 \text { to accom- } \\
\text { modate the new payment mechanism }\end{array}$ \\
\hline Database management & SQL server & Oracle & Oracle \\
\hline
\end{tabular}

$D R G$ Diagnosis-Related Group, INA-CBG Indonesia Case-Based Group

2014 but was still under development and refinement until the start of 2015. Within BPJS Kesehatan, there are three main databases that are managed by SQL server and are interconnected: (1) membership database; (2) financial database; and (3) health services utilization database.

In Vietnam, claims have been electronically recorded and stored in an Oracle (C) database since 1 January 2016. A pilot phase was then rolled out over the year, including some government hospitals. Since 1 January 2017, it has been mandatory for all hospitals to register patients in the database and input data directly into the VHIS database server in order to receive reimbursement.

Updating of the PhilHealth database, managed by Oracle (C), was carried out in 2012 to accommodate the shift in provider payment scheme from fee-for-service to ACR. The claims payment has run electronically since 1998, using the system of its predecessor, Medicare. The non-medical adjudication stage was only automated in 2016, while the prepayment medical audit system is currently being developed.

\subsection{Description of Data Capture}

Coverage of national health insurance stood at $75 \%$ in 2018 for Indonesia, 84\% in 2017 for Vietnam, and 91\% in 2016 for the Philippines, as reported in Table 2. Across all these three countries, non-enrollees of the SHI programmes included those in the lower-income category, working in the informal sector, or having private insurance [27]. While JKN and PhilHealth accredit almost equal proportions of public and private facilities, the VHIS includes only a small portion of private facilities. Electronic data capture started in 2014 for JKN and 2017 for VHIS. PhilHealth revamped its database in 2012, but e-claims only started in 2016. The most recent year of completed claims for JKN, VHIS and PhilHealth are 2016, 2018 and 2017, respectively. There is a variable degree of data capture for all three databases, which is closely related to the respective financing systems. VHIS consistently and continuously captures data on care at all levels (primary, secondary and tertiary), while PhilHealth comprehensively captures hospitalization claims. In contrast, while inpatient and specialist outpatient records are captured consistently in JKN, primary care data do not include health expenditure due to its capitation scheme. Data for all three databases are available at the patient level.

\subsubsection{Record Length and Latency}

The JKN database contains 3 years of complete records, from 2014 to 2016. PhilHealth (2016 and 2017) and VHIS (2017 and 2018) have 2 years of complete data. JKN claims are first filed by hospitals, which are then electronically and manually verified by BPJS. The process takes approximately 2 months to 1 year before the claims are registered in the database. In Vietnam, hospital and clinic administrators enter data into the centrally managed VHIS server. Claims are submitted within 2 months of a medical visit. Large hospitals in the Philippines encode claims directly into the system, while the rest of the facilities send hard copies of claims to the regional PhilHealth offices for encoding. In $2017,66 \%$ of the facilities submitted claims electronically. It takes approximately 2 months for submissions to be recorded in the database. All social security agencies have in-house information technology (IT) personnel to extract data either for internal use or for academic research.

\subsubsection{Data Variables}

Variables available in each database are shown in Table 3. The JKN database contains diagnoses identified by ICD-10 codes for both outpatient visits and inpatient admissions, as 
Table 2 Description of the JKN, VHIS and PhilHealth databases

\begin{tabular}{|c|c|c|c|}
\hline & JKN & VHIS & PhilHealth \\
\hline Population coverage (year) & $75 \%$ or 197 million $(2018)$ & $84 \%$ or 81 million (2017) & $91 \%$ or 94 million (2016) \\
\hline Health facilities coverage (year) & (2017) & $(2015)$ & (2017) \\
\hline Number of providers & 25,391 & 13,508 & 6118 \\
\hline Outpatient & 22,975 & 12,143 & 8127 \\
\hline Clinics & 20,300 & 345 & $1541^{\mathrm{a}}$ \\
\hline Private $(\%)$ & 51 & 0 & 0 \\
\hline Rural health units & NA & 11,798 & 2606 \\
\hline Retail pharmacies & 2675 & None & None \\
\hline Others (infirmaries and birthing homes) & NA & NA & 2067 \\
\hline Hospitals & 2416 & 1365 & 1913 \\
\hline Private $(\%)$ & 60 & 13 & 60 \\
\hline Continuous and consistent data capture & $\begin{array}{l}\text { Yes, only for specialist outpatients and } \\
\text { inpatients }\end{array}$ & Yes & Yes, only for inpatients \\
\hline $\begin{array}{l}\text { Record duration of complete data, as of } \\
\text { February } 2019\end{array}$ & 3 years $(2014-2016)$ & 2 years (2017-2018) & 2 years (2016-2017) \\
\hline Data latency & $\begin{array}{l}2 \text { months to } 1 \text { year, depending on how } \\
\text { prompt hospitals are with filing of claims }\end{array}$ & $2-4$ months & 2 months \\
\hline Number of claims (year) & $\sim 50$ million $(2015)$ & 200 million (2017) & $\sim 10$ million $(2016)$ \\
\hline In-house database expertise & Yes & Yes & Yes \\
\hline
\end{tabular}

JKN Jaminan Kesehatan Nasional, VHIS Vietnam Health Insurance Scheme, PhilHealth Philippine Health Insurance Corporation, NA not applicable

${ }^{a}$ Only includes facilities accredited to provide primary care benefits

well as the INA-CBG for inpatient admissions. INA-CBG differentiates the severity of disease based on complications and comorbidities, which may or may not be present in the database. It is not detailed enough for certain diseases, such as cancer staging. Utilization of health resources, such as prescriptions, laboratory tests or medical supplies, is reported as a bundled cost, with resource intensity being aligned with the severity levels in the INA-CBG. This poses difficulty in understanding the type of care received by the beneficiaries. The pharmacy database does not fully capture all drug information. Inpatient pharmacy data registers drugs that are unbundled. Outpatient pharmacy data captures information regarding drugs covered in the PRB.

The VHIS database contains comprehensive information, including both primary and tertiary care, and adopts international coding for diagnoses. Medical procedures are coded using a domestic coding system, which is adapted from the International Classification of Diseases, Ninth Revision, Clinical Modification (ICD-9-CM) classification system and tailored to local practice. Only information regarding drugs reimbursed by the VHIS is captured in the database. Drugs not listed in the formulary and paid OOP are not recorded. Additionally, only prescribed OTC drugs, but not those obtained from retail pharmacies, are logged.

The PhilHealth database contains mainly inpatient data, and diseases are identified using ICD-10 codes. Like the
JKN database, it primarily captures the reimbursed amount. Co-payments and total hospital bills are largely underreported as these are not mandatory fields. The reimbursed amount comprises room and board, medicines, professional fees, and laboratory and operating room costs. Although PhilHealth reimburses indigent patients with the Primary Care Benefit package, the resource utilization and medical costs in the primary care setting are not captured in the database as these are stored in a separate server under the DOH. Surgical procedures are coded based on the RVS, which is patterned after the nomenclature of the American Clinical Procedure Terminologies [28]. Information on reimbursed drugs is not captured in the database.

\subsection{Linkage to Other Databases or Registries}

The databases under evaluation have never been linked to any other databases or registries, in both formal or informal studies; however, there is the possibility of linking to hospital databases and national registries via unique health insurance membership numbers or national identification numbers. The latter is subject to the reliability and representativeness of data collected in the registries, as fully functioning population-based registries are still scarce in these countries. There is a considerable challenge in establishing a protocol for maintaining privacy during data linkage 
Table 3 Data variables available in the JKN, VHIS and PhilHealth databases

\begin{tabular}{|c|c|c|c|}
\hline Variables & JKN & VHIC & PhilHealth \\
\hline Unique patient identification number & $\sqrt{ }$ & $\sqrt{ }$ & $\sqrt{ }$ \\
\hline \multicolumn{4}{|l|}{ Demographics } \\
\hline Sex & $\sqrt{ }$ & $\sqrt{ }$ & $\sqrt{ }$ \\
\hline Age & $\sqrt{ }$ & $\sqrt{ }$ & $\sqrt{ }$ \\
\hline Ethnicity & $\mathrm{x}$ & $\sqrt{ }$ & NA \\
\hline Patient residence (region) & $\mathrm{x}$ & $\sqrt{ }$ & $\sqrt{ }$ \\
\hline Urban or rural & $\sqrt{ }{ }^{\mathrm{a}}$ & $\sqrt{ }$ & $\sqrt{ }$ \\
\hline Membership category & $\sqrt{ }$ & $\sqrt{ }$ & $\sqrt{ }$ \\
\hline \multicolumn{4}{|l|}{ Other patient information } \\
\hline Height & $\mathrm{X}$ & $\mathrm{x}$ & $\mathrm{X}$ \\
\hline Weight & $\mathrm{X}$ & $\mathrm{x}$ & $\mathrm{X}$ \\
\hline Smoking status & $\mathrm{x}$ & $\mathrm{x}$ & $\mathrm{x}$ \\
\hline \multicolumn{4}{|l|}{ Primary/outpatient care } \\
\hline Date of visit & $\sqrt{ }$ & $\sqrt{ }$ & $\sqrt{ }$ \\
\hline Diagnosis (coding) & $\sqrt{ }(\mathrm{ICD}-10)$ & $\sqrt{ }(\mathrm{ICD}-10)$ & $\sqrt{ }(\mathrm{ICD}-10)$ \\
\hline Drug information & Only for drugs covered under $\mathrm{PRB}^{\mathrm{b}}$ & $\sqrt{ }$ & $\mathrm{x}$ \\
\hline Domestic coding system & $\mathrm{X}$ (only molecule names) & $\sqrt{ }$ & $\mathrm{x}$ \\
\hline Prescription date & $\sqrt{ }$ & $\sqrt{ }$ & $\mathrm{x}$ \\
\hline Quantity & $\sqrt{ }$ & $\sqrt{ }$ & $\mathrm{x}$ \\
\hline Drug administration & $\mathrm{x}$ & $\sqrt{ }$ & $\mathrm{x}$ \\
\hline Dose strength & $\mathrm{x}$ & $\sqrt{ }$ & $\mathrm{x}$ \\
\hline Frequency of use & $\sqrt{ }$ & $\sqrt{ }$ & $\mathrm{x}$ \\
\hline Procedure (coding) & $\sqrt{ }$ & $\sqrt{ }$ & $\sqrt{ }$ \\
\hline Laboratory tests & $\mathrm{x}$ & $\sqrt{ }$ & $\mathrm{X}$ \\
\hline Health expenditure (reimbursed) & $\mathrm{x}$ & $\sqrt{ }$ & $\mathrm{x}$ \\
\hline Health expenditure (co-payment) & $\mathrm{x}$ & $\sqrt{ }$ & $\mathrm{x}$ \\
\hline \multicolumn{4}{|l|}{ Inpatient care and emergency care } \\
\hline Date of admission & $\sqrt{ }$ & $\sqrt{ }$ & $\sqrt{ }$ \\
\hline Date of discharge & $\sqrt{ }$ & $\sqrt{ }$ & $\sqrt{ }$ \\
\hline Death & $\sqrt{ }$ & $\mathrm{x}$ & $\sqrt{ }$ \\
\hline Discharge diagnosis (coding) & $\sqrt{ }(\mathrm{ICD}-10)$ & $\sqrt{ }(\mathrm{ICD}-10)$ & $\sqrt{ }(\mathrm{ICD}-10)$ \\
\hline Other diagnosis codes & $\sqrt{ }(\mathrm{ICD}-10)$ & $\sqrt{ }(\mathrm{ICD}-10)$ & $\sqrt{ }(\mathrm{ICD}-10)$ \\
\hline Drug information & Only for unbundled drugs & $\sqrt{ }$ & $\mathrm{X}$ \\
\hline Domestic coding system & $\mathrm{X}$ (only molecule names) & $\sqrt{ }$ & $\mathrm{x}$ \\
\hline Prescription date & $\sqrt{ }$ & $\sqrt{ }$ & $\mathrm{x}$ \\
\hline Quantity & $\sqrt{ }$ & $\sqrt{ }$ & $\mathrm{x}$ \\
\hline Drug administration & $\mathrm{x}$ & $\sqrt{ }$ & $\mathrm{x}$ \\
\hline Dose strength & $\sqrt{ }$ & $\sqrt{ }$ & $\mathrm{x}$ \\
\hline Frequency of use & $\sqrt{ }$ & $\sqrt{ }$ & $\mathrm{X}$ \\
\hline Procedure (coding) & $\sqrt{ }($ ICD-9-CM $)$ & $\sqrt{ }($ domestic coding $)$ & $\sqrt{ }($ relative value scale $)$ \\
\hline Laboratory tests & $\mathrm{x}$ & $\sqrt{ }$ & $\mathrm{X}$ \\
\hline Hospital code & $\sqrt{ }$ & $\sqrt{ }$ & $\sqrt{ }$ \\
\hline Level of hospital & $\sqrt{ }$ & $\sqrt{ }$ & $\sqrt{ }$ \\
\hline Location of hospital & $\sqrt{ }$ & $\sqrt{ }$ & $\sqrt{ }$ \\
\hline Health expenditure (co-payment) & $\mathrm{x}$ & $\sqrt{ }$ & $\sqrt{ }$ \\
\hline Health expenditure (reimbursed) & $\sqrt{ }$ & $\sqrt{ }$ & $\sqrt{ }$ \\
\hline Notable exclusions from coverage & Prophylactics; aesthetic procedures & $\begin{array}{l}\text { Prophylactics; aesthetic } \\
\text { procedures }\end{array}$ & $\begin{array}{l}\text { Alcohol abuse; fifth and subsequent normal } \\
\text { obstetrical deliveries; same illness within } \\
90 \text { days; aesthetic procedures }\end{array}$ \\
\hline
\end{tabular}

$J K N$ Jaminan Kesehatan Nasional, VHIS Vietnam Health Insurance Scheme, PhilHealth Philippine Health Insurance Corporation, NA not applicable, ICD-9-CM International Classification of Diseases, Ninth Revision, Clinical Modification, ICD-10 International Classification of Diseases, Tenth Revision

${ }^{a}$ Based on the household residence, not the current place of residence

${ }^{\text {b} P R B ~ r e f e r s ~ t o ~ P r o g r a m ~ R u j u k ~ B a l i k, ~ o r ~ b a c k-r e f e r r a l ~ p r o g r a m m e, ~ s p e c i f i c a l l y ~ f o r ~ p a t i e n t s ~ w i t h ~ c h r o n i c ~ d i s e a s e s, ~ n a m e l y ~ h y p e r t e n s i o n, ~ d i a b e t e s ~ m e l l i-~}$ tus, asthma, chronic obstructive pulmonary disease, epilepsy, stroke, systemic lupus erythematosus, schizophrenia and chronic ischaemic heart disease 
Table 4 Accessibility of the JKN, VHIS and PhilHealth databases

\begin{tabular}{|c|c|c|c|}
\hline Criteria & JKN & VHIS & PhilHealth \\
\hline IRB approval required & No & No & No \\
\hline Protocol required & No & Yes & No \\
\hline Specify variables required & Yes & Yes & Yes \\
\hline Fees & No & Yes & Yes \\
\hline Collaboration with data custodian required & No & Yes & Yes \\
\hline $\begin{array}{l}\text { Accessible to researchers from other } \\
\text { countries }\end{array}$ & Yes & Yes & Yes \\
\hline
\end{tabular}

$J K N$ Jaminan Kesehatan Nasional, VHIS Vietnam Health Insurance Scheme, PhilHealth Philippine Health Insurance Corporation, IRB Institutional Review Board

between different institutions or organizations. In the Philippines, there is movement towards a Philippine Health Information Exchange plan, which aims to link electronic medical records and health management information systems across facilities, and harmonize information between PhilHealth and the DOH. Once the plan is complete, all patient records will be submitted to a central system, which will be linked to registries, allowing both healthcare providers and patients to retrieve patient's health information; however, as there is neither a national ID nor a national health ID, this remains a challenge.

\subsection{Data Access and Extraction}

Data are kept privately and are only available upon request. The format and type of data output can be requested from the social security agencies. Procedures on data access differ among agencies, as shown in Table 4 . To access the databases, researchers need to collaborate with custodians from the social security agencies. A letter of intent, together with a research proposal and the type of data variables needed, are required.

For the JKN database, a letter of request must first be addressed to the Chief of Director of BPJS. The request will then be processed by the Information Management and Documentation Office (also known as Pejabat Pengelola Informasi dan Dokumentasi [PPID]). Researchers will be notified of the final decision within 6 months. Access to the data is subject to the queuing system, which is based on a first-come, first-served basis and priority of the studies. Researchers will be scheduled a time slot to analyse the results on-site using assigned workstations. Only aggregate results can be exported.

The Vietnam Health Economics Association (VHEA) is the authorized partner of VSS for health economic analyses. As it has sole access to the VHIS, requests for database access will have to be processed and agreed upon by the VHEA before being considered by the VSS. A request takes 2 to 4 weeks to be processed from each organization.
Data extraction is conducted by the VSS, while data analyses according to the pre-agreed analysis plan with researchers is conducted by the VHEA. Outputs are extracted as aggregate results. There is a standard fee schedule for data access, depending on the size of the data.

Researchers interested in accessing the PhilHealth database request data through the Corporate Planning Department of PhilHealth. PhilHealth charges an administrative fee based on the size of the data extracted. The time needed to extract the data depends on the magnitude and scope of the analyses. Health conditions that are also the government's public health priorities could receive prompt attention, minimizing process duration.

\subsection{Privacy and Security}

All social security agencies adhere to the local privacy laws by protecting patient records and keeping patient identifiers private. These identifiers may include name, membership number, national identification number (if available), birth date and addresses. Researchers work with pseudo-identifiers, if they are provided with the dataset.

According to Indonesia's Public Information Disclosure Act, Clause $17 \mathrm{~h}$, medical histories and conditions, treatments, and medications of patients cannot be made public [29]. In the Philippines, the Republic Act. No. 10173, Ch. 1, Sec. 2, stipulates that sharing of data must be covered by an agreement that provides adequate safeguards for the rights of data subjects in the Philippines. In Vietnam, Article 3 of law 25/2008/QH12 [30] governs that health data should be confidential unless agreed by the individual; however, these prohibitions can be overcome if researchers request anonymized data. To further protect an individual's privacy, the BPJS only allows researchers to conduct individual-level data analyses on-site and to export aggregate results.

\subsection{Quality and Validation Procedures}

The validation of data in all databases has not previously been formally evaluated. All health insurances have reported cases of upcoded diagnoses, meaning claims could be guided by the diagnosis code with the higher reimbursement rate, instead of reflecting the actual condition. While some verification has been conducted to ensure claims are appropriately coded for JKN and PhilHealth, this is not the case for the VHIS. Nonetheless, researchers could request the VHEA to conduct logical checks on the extracted dataset. The digital verification system VEDIKA in BPJS, verifies claims and reimburses hospitals within 15 days. The BPJS will manually investigate anomalies that are flagged by the system. PhilHealth conducts a medical post-payment audit for leading illnesses claims in the claims reimbursement, including community-acquired pneumonia, acute gastroenteritis, 
dengue, and urinary tract infections [31]. All other diseases are not being audited. To counter malpractices of upcoding, PhilHealth requires claims to be accompanied by a statement of accounts, which will be checked against the diagnoses and/or procedures in the claim form.

\section{Discussion}

Although coverage of SHI in Indonesia, Vietnam and the Philippines is lower than other Asian countries, for example 98\% in Thailand and 100\% in Malaysia [18], these databases are plausible data sources for health research, even when considering their limitations. Overall, all three databases provide population-based cohort data on reimbursed medical conditions based on ICD-10 codes and medical cost. These databases could be enhanced if linkage to other national databases, such as registries, was possible; however, since this is an unprecedented step, challenges regarding the technical issues and preservation of patient privacy are expected and should be overcome. As access to these data varies among the different social security agencies, working with the respective data custodians is important in facilitating the process.

There are a few noteworthy limitations for all three databases. First, the databases are fairly new and contain a rather short span of data records. Another limitation is the issue of upcoding; the prevalence and extent of upcoding in these databases have not been formally studied. All three countries implement either case-based or fee-for-service provider-payment mechanisms, which indirectly incentivize upcoding among healthcare providers for receiving a larger reimbursement [32]. This informal relationship between provider-payment mechanisms and the incentives among providers for fraud and upcoding should always be taken into account by researchers as there is a risk of identifying certain health problems as more severe than what they are, resulting in skewed data that may not be representative of the true population health status. Future research could shed light on the degree of accuracy and validity of recorded data by comparing claims data with medical records. Comparing healthcare resources and expenditure across all these databases could be possible with common disease coding, albeit challenging, given the varying level of information in each database. Unless combined with other datasets, JKN bundled claims data may be more appropriate for examining issues related to access to health care, and prevalence of medical conditions among the insured members (given the incomplete nationwide coverage), rather than the actual resource utilization. The use of PhilHealth data is more suitable for research on serious medical conditions.

\subsection{Comparison with Other Studies on National Claims Databases}

Two studies have evaluated national claims databases in Asia; one study was based on surveys with investigators who owned or used the databases [5], and the other assessed the databases through literature and contacts with data custodians [18]. The databases evaluated included the National Health Insurance Research Database (NHIRD) in Taiwan; Health Insurance and Review Assessment (HIRA) in South Korea; Japan National Database (JND); reimbursement databases in Thailand, which includes a universal coverage scheme, civil servant medical benefits scheme and a social security scheme; and the Medisave database in Singapore. Both studies did not evaluate VHIS, JKN and PhilHealth. Notably, the database structure and contents are known for the NHIRD, HIRA and JND [5]. Similar to these databases, VHIS, JKN and PhilHealth identify diseases based on the ICD, and anonymized data are available at the patient level. The VHIS, but not JKN and PhilHealth, has a database comparable to national claims databases in Taiwan (NHIRD) and Korea (HIRA), with comprehensive records on demographic and administrative information [5, 18]. Key differences between claims databases in Taiwan, South Korea and Japan, as well as those evaluated in this study, include the record duration, coding system for drugs and linkage to registries. Unlike the NHIRD, HIRA and JND, which were established a decade or more ago, VHIS, JKN and PhilHealth lack longterm data for outcomes research, which preclude studies aimed at exploring temporal trends of diseases. While the NHIRD, HIRA and JND classify drugs using the Anatomical Therapeutic Chemical (ATC) classification system, the JKN uses drug names and the VHIS uses domestic coding. Lastly, both the NHIRD and HIRA can be linked to other registries [33], and this has yet to be explored in Vietnam, Indonesia and the Philippines, a move that could augment the database with clinical information.

\subsection{Strengths and Limitations of the Study}

The information in this study was provided by data custodians, which ensures that the most recent information has been accurately reported in this publication. The current study provides researchers with a general understanding of the SHI claims databases and its access in Indonesia, Vietnam and the Philippines, and is not intended to replace specific advice or requirements from the respective social security agencies. A limitation of the study is that it assessed the databases qualitatively, not quantitatively. Feasibility and accessibility of these databases could be assessed using a scoring system in future. 


\section{Conclusion}

This research study presents an overview of the healthcare administrative databases in Indonesia, Vietnam and the Philippines, and evaluates their feasibility and accessibility for research. The main finding of this study was that valuable information is routinely recorded in the claims databases, which could be used for providing country-specific epidemiological and economic evidence. Despite several limitations, leveraging these databases for research may be more advantageous than conducting surveys or chart reviews. The results from such studies may be used to inform clinical practice and health policy decisions.

Acknowledgements The authors would like to recognize the valuable input from Ms. Celina Gacia from the Philippine Department of Health, Dr. Lala Sabido and Mr. Vergil M. De Claro from the Philippine Health Insurance Corporation, and Miss Sirinthip Petcharapiruch from IQVIA Asia-Pacific for being part of the conceptualization of this study. The authors would also like to thank Miss Evanthia Achilla from IQVIA Asia-Pacific for her constructive criticism of this manuscript.

Author Contributions JYSN conceptualized the study and drafted the manuscript. RVR and PHTK carried out the analyses. All authors contributed to the writing and critical review of the manuscript for intellectual content.

\section{Compliance with Ethical Standards}

Funding No funding was received for the conduct of this study and none of the authors received any financial support for the preparation of this manuscript.

Conflict of interest Donni Hendrawan and Pham Huy Tuan Kiet report previously receiving funding from Novo Nordisk as experts. Junice Yi Siu Ng is employed by IQVIA, a contract research organization. Royasia Viki Ramadani and Duong Tuan Duc declare that they have no conflicts of interest.

Data Availability Statement The data that support the findings of this study are available from IQVIA Asia-Pacific; however, restrictions apply to the availability of these data and therefore they are not publicly available. Nonetheless, data are available from the authors upon reasonable request and with permission from IQVIA Asia-Pacific.

Open Access This article is distributed under the terms of the Creative Commons Attribution-NonCommercial 4.0 International License (http://creativecommons.org/licenses/by-nc/4.0/), which permits any noncommercial use, distribution, and reproduction in any medium, provided you give appropriate credit to the original author(s) and the source, provide a link to the Creative Commons license, and indicate if changes were made.

\section{References}

1. Jones GW. The Population of South-East Asia. Singapore: Asia Research Institute; 2013.

2. OECD/WHO. Health at a glance: Asia/Pacific 2016. Paris: OECD Publishing; 2016.
3. Bezin J, Duong M, Lassalle R, Droz C, Pariente A, Blin P, et al. The national healthcare system claims databases in France, SNIIRAM and EGB: powerful tools for pharmacoepidemiology. Pharmacoepidemiol Drug Saf. 2017;26(8):954-62.

4. Kim J, Yoon S, Kim L-Y, Kim D-S. Towards actualizing the value potential of Korea Health Insurance Review and Assessment (HIRA) data as a resource for health research: strengths, limitations, applications, and strategies for optimal use of HIRA data. J Korean Med Sci. 2017;32(5):718-28.

5. Lai EC-C, Man KK, Chaiyakunapruk N, Cheng C-L, Chien $\mathrm{H}-\mathrm{C}$, Chui CS, et al. Brief report: databases in the Asia-Pacific region: the potential for a distributed network approach. Epidemiology. 2015;26(6):815-20.

6. Smeets HM, de Wit NJ, Hoes AW. Routine health insurance data for scientific research: potential and limitations of the Agis Health Database. J Clin Epidemiol. 2011;64(4):424-30.

7. Tessier-Sherman B, Galusha D, Taiwo OA, Cantley L, Slade MD, Kirsche SR, et al. Further validation that claims data are a useful tool for epidemiologic research on hypertension. BMC Public Health. 2013;13:51.

8. Bright RA, Avorn J, Everitt DE. Medicaid data as a resource for epidemiologic studies: strengths and limitations. J Clin Epidemiol. 1989;42(10):937-45.

9. Green J, Wintfeld N. How accurate are hospital discharge data for evaluating effectiveness of care? Med Care. 1993;31(8):719-31.

10. Motheral BR, Fairman KA. The use of claims databases for outcomes research: rationale, challenges, and strategies. Clin Ther. 1997;19(2):346-66.

11. Dresser MV, Feingold L, Rosenkranz SL, Coltin KL. Clinical quality measurement: comparing chart review and automated methodologies. Med Care. 1997;35:539-52.

12. Van Panhuis WG, Paul P, Emerson C, Grefenstette J, Wilder R, Herbst AJ, et al. A systematic review of barriers to data sharing in public health. BMC Public Health. 2014;14(1):1144.

13. Social Security Administration. Social security programs throughout the world: Asia and the Pacific, 2016. Social Security Administration; 2017.

14. The World Bank Open Data. The World Bank; 2018.

15. Nguyen MP, Wilson A. How could private healthcare better contribute to healthcare coverage in Vietnam? Int J Health Policy Manag. 2017;6(6):305-8.

16. Bersales LGS. Manila. Manila: Philippine Statistics Authority; 2016. p. 2017.

17. Gool MJA. Integrating Casemix system in to the Philippine social health insurance. BMC Health Serv Res. 2012;12(S1):I6.

18. Milea D, Azmi S, Reginald P, Verpillat P, Francois C. A review of accessibility of administrative healthcare databases in the AsiaPacific region. J Mark Access Health Policy. 2015;3(1):28076.

19. Shihab AN, Nurdin A, Kadir A, Thabrany H, Paturusi I. National health insurance effects on inpatient utilization in Indonesia. Int J Health Sci Res. 2017;7(4):96-106.

20. Atmiroseva A, Nurwahyuni A. Inpatient readmission incidence of national health insurance patients at partner hospitals of BPJS-Health in Sukabumi 2015. J Indones Health Policy Adm. 2017;2(2):20-4.

21. Sari RP. Comparison of actual costs with INA-CBG rates and factors associated with costs of diabetes mellitus in patients in Hospital Sardjito Yogyakarta. Jurnal Ilmiah Bisnis dan Keuangan (Bus Financ Sci J). 2016;4(1):102-12.

22. Wagner AK, Valera M, Graves AJ, Laviña S, Ross-Degnan D. Costs of hospital care for hypertension in an insured population without an outpatient medicines benefit: an observational study in the Philippines. BMC Health Serv Res. 2008;8(1):161.

23. Tumanan-Mendoza BA, Mendoza VL, Frias MVG, Bonzon DD. Economic burden of community-acquired pneumonia among 
pediatric patients (aged 3 months to $<19$ years) in the Philippines. Value Health Reg Issues. 2017;12:115-22.

24. Tumanan-Mendoza BA, Mendoza VL, Bermudez-Delos Santos AA, Punzalan FE, Pestano NS, Natividad RB, et al. Epidemiologic burden of hospitalisation for congestive heart failure among adults aged $\geq 19$ years in the Philippines. Heart Asia. 2017;9(1):76-80.

25. Tobe M, Stickley A, del Rosario RB, Jr Shibuya K. Out-of-pocket medical expenses for inpatient care among beneficiaries of the National Health Insurance Program in the Philippines. Health Policy Plan. 2013;28(5):536-48.

26. Hall GC, Sauer B, Bourke A, Brown JS, Reynolds MW, LoCasale R. Guidelines for good database selection and use in pharmacoepidemiology research. Pharmacoepidemiol Drug Saf. 2012;21(1):1-10.

27. Van Minh H, Pocock NS, Chaiyakunapruk N, Chhorvann C, Duc HA, Hanvoravongchai P, et al. Progress toward universal health coverage in ASEAN. Glob Health Act. 2014;7(1):25856.
28. Philippine Health Insurance Corporation. Relative value scale: manual of procedures. Manila: Philippine Health Insurance Corporation; 2010.

29. Ministry of Law and Human Rights (ed). Public Information Disclosure Act. Jakarta: Ministry of Law and Human Rights; 2008.

30. The National Assembly (ed). Law on Medical Examination and Treatment. Socialist Republic of Vietnam; 2009.

31. Philippine Health Insurance Corporation. Policy on Claims for Pneumonia, Acute Gastroenteritis, Urinary Tract Infection and Other Identified Conditions. The Philippines: Philippine Health Insurance Corporation; 2017. PhilHealth Circular No. 2017-0028.

32. Kari F, Bryan B, Paul J. The use of claims data in healthcare research. Open Public Health J. 2009;2(1):11-24.

33. Hsing AW, Ioannidis JP. Nationwide population science: lessons from the Taiwan national health insurance research database. JAMA Intern Med. 2015;175(9):1527-9. 